\title{
Social partners cooperation for reduction of musculoskeletal disorders in agriculture
}

\author{
Veerle Hermans ${ }^{\mathrm{a}, \mathrm{b}^{*}}$, David O’Neill ${ }^{\mathrm{c}}$, Roeland Motmans ${ }^{\mathrm{a}}$, Peter Lundqvist ${ }^{\mathrm{d}}$ and Danuta Roman-Liu ${ }^{\mathrm{e}}$ \\ ${ }^{a}$ Department of Ergonomics, IDEWE, External Prevention Service for Safety and Health at Work, Interleuvenlaan \\ 58, B-3001 Heverlee, Belgium \\ ${ }^{\mathrm{b}}$ Department of Work Psychology, Vrije Universiteit Brussel, Pleinlaan 2, B-1050 Brussels, Belgium \\ ${ }^{\mathrm{c}}$ Department of Ergonomics, University of Loughborough, Leicestershire, LE11 3TU, UK \\ ${ }^{\mathrm{d}}$ Department of Work Science, Business Economics and Environmental Psychology, Swedish University of Agri- \\ cultural Sciences, Box 88, S- 23053 Alnarp, Sweden \\ ${ }^{\mathrm{e}}$ Department of Ergonomics, Central Institute for Labour Protection- National Research Institute, 16 \\ Czerniakowska str., 00-701 Warsaw, Poland
}

\begin{abstract}
The European social partners in agriculture recognize the considerable frequency of musculoskeletal disorders (MSD) in the sector which has negative consequences for workers, employers, social security systems and hence for the whole society. They made an agreement in 2005 to tackle this problem and their main interest was finding good practices 'on the floor', with the involvement of the farmers and farming industries. A partnership with researchers from 4 different organisations across Europe, was created, taking into account both academic partners and/or partners experienced with the agricultural sector. GEOPA-COPA acted as a network partner with all the EU agriculture organisations. The project partners proposed a methodology how to collect the good practices. In total, 103 company visits were organised and 55 additional reports were collected. More than 140 good practices were defined going from easy, low-cost solutions to highly technological, more expensive solutions. All this information is disseminated via the project website (www.agri-ergonomics.eu) and summarised in 6 brochures. This paper focuses on the methodology to set up the ergonomic project with social partners.
\end{abstract}

Keywords: agriculture, musculoskeletal disorders, good practices, social partners

\section{Introduction}

A lot of workers in the agriculture sector suffer from musculoskeletal disorders (MSD). Although there are limitations on the extent of the injuries and illnesses due to incomplete data, there is no doubt that this problem exceeds all other types of injury and diseases in the sector and also exceeds other sectors. For example in the USA, the prevalence rate of MSD in agriculture is 1,5 times that of industry in general. And MSD cost the farming industry in excess of $\$ 168$ million, without including lost productivity and human costs [4]. Also population-based surveys reveal a considerable number of farmers and farm workers who have musculoskeletal problems.
Recent data from the European Survey for Working conditions [9] mention that $54 \%$ of the agriculture workers spend at least half of the time in tiring or painful positions during work. In addition, 38\% mentions carrying or moving loads and $55 \%$ have to perform repetitive hand/arm movements. Last but not least, $62 \%$ of the farmers report having suffered from backache and $56 \%$ of muscular pains in the upper limbs over the last 12 months.

The sector comprises several different branches such as production of crops and raising of livestock, which includes a wide diversity of work tasks.In these tasks, several manual handling operations are found and have been mentioned as important risk factors for the development of MSD. Heavy loading

\footnotetext{
${ }^{*}$ Corresponding author. E-mail: veerle.hermans@idewe.be
} 
of joints (e.g. during manual handling) and wholebody vibration (e.g. during tractor driving) are mentioned as important risk factors [13]. Also awkward postures while harvesting or milking cows are important risks for MSD. Most MSDs are therefore found in the following subsectors: production of meat, viniculture, horticulture, breeding of small animals and processing of poultry meat [3].

To maintain agriculture as an attractive sector for workers and for the competitiveness of the farming industry, a safe and healthy working environment for agricultural workers is essential, taking into account prevention of the MSD risk factors. The social partners in agriculture, GEOPA-COPA (the United voice of farmers and cooperatives) and EFFAT (Trade Unions Food-Agriculture-Tourism), agreed in 2005 to engage in sector negotiations on this topic with the aim of formulating a number of concrete proposals on the reduction of workers' exposure to the risk of work-related MSD [5]. To help the social partners with this, a group of researchers worked together in collecting today's good practices for six typical agricultural tasks. This papers focuses on the methodology that was created by the project partners.

\section{Methodology}

\subsection{Development of the partnership}

Four different member states of the European Union (EU) were active in the visits and collection of good practices. The partners had important links with the national social partners' organisations, which guaranteed well-prepared meetings and visits. A balanced partnership was present, taking into account both academic partners and/or partners experienced with the agricultural sector. GEOPA-COPA acted as a network partner with all the EU agriculture organisations so that extra emphasis was given on social dialogue and collaboration and transmission of information, results and feedback across all Member States. IDEWE acted as project coordinator and was responsible for communication with the EU and for standardising the approach of all project members.

\subsection{Involvement of the social partners}

The social partners in agriculture were involved in the project on several occasions:

- The European partners were informed by the project manager regarding the objectives and meth- odology of the project. They were asked for cooperation of all their member states.

- Cooperation was requested form the national social partners organizations to help them to contact farms and organisations.

- During each farm visit there was an interview with the worker and the employer (if not selfemployed) regarding MSD problems and solutions. Remarks were noted on a standard good practice document (figure 2).

- In between reporting to the EU social partners was possible via the network partner COPACOGECA, who presented the status of the project during internal meetings.

- Finally, the EU social partners were invited to the seminar at the end of the project.

\subsection{Definition of good practices}

The definition of a good practice (GP) is based on two concepts described by the European Agency for Safety and Health at Work [6]. First, a GP is not necessarily basic research information, nor policy information, nor general knowledge. And second, the GP is a successful solution to occupational safety and health risks: it provides guidance information and documentation and/or case studies. The implementation of a GP should lead to a reduction of the whole potential to cause harm to workers and an improvement of working conditions.

These case-study examples can be considered as innovations defined by Kramer et al. [12] as a set of processes, tools or materials that have the potential for preventing MSDs, but that do not necessarily need to be new inventions. The purpose was really to find examples in current use and compatible with contemporary farming practice, and acceptable to the prevailing cultural conditions. This means especially including both low-cost solutions and the more hightechnology developed practices. This methodology takes also into account the recommendations of Kogi [8]: for small enterprises, emphasis should go to lowcost solutions learned from local good practices. An example is given in figure 1 , representing a low-cost solution and a robotic solution for milking cows.

Of course the views of farmers themselves on good practices may be sometimes ergonomically naïve and subjectively influenced or constrained by local circumstances. Therefore, the additional remarks of the ergonomists regarding the evaluated good practice are important information and were included to the standard documents. For example, 
regarding the milking chair, there may be some relief of the load, but still awkward sitting postures are still present.
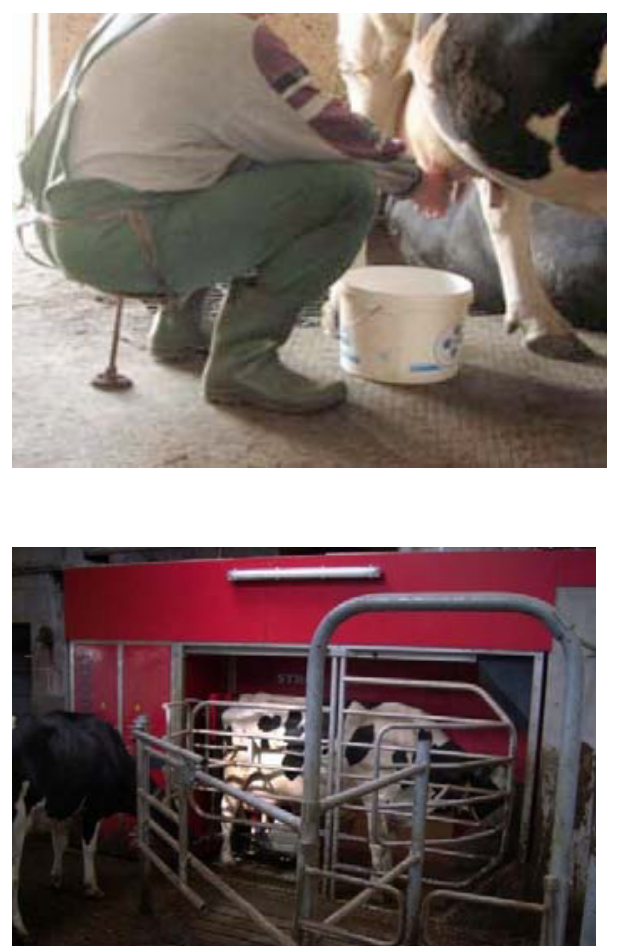

Figure 1: Two examples of good practices for milking cows: a milking chair and a robot.

\subsection{Collection of good practices}

A standard approach for the collection of information was adopted:

- Definition of agricultural tasks. The agricultural sector is very large (NACE code 01 ). It is impossible to collect good practices for all different subsectors and tasks. Therefore, the social partners agreed to collect practices for six representative tasks: milking cows (task 1), tractor driving (task 2), ground level manual crops (task 3), pruning (task 4), sorting (task 5), harvesting (task 6).

- Meetings were organised with national social partners to collect existing information, references and contacts in the sector. From this, visits to farms or companies were organised, taking into ac- count seasonal differences and daily working practices for each of the six tasks. During the meetings of the project partners, the results of these visits were presented to each other to validate and cross-check the choice of working practices and to check possible preventive solutions already present in the field;

- Participants attending the European social partners meetings were asked to send existing cases or information to the project partners.

Presentation of the GP had to be performed using a standard document with the following information (for example, figure 2) : (1) description of the work tasks, (2) comments of the employee(s), (3) comments of the employer (if present), (4) physical MSD risk factors, (5) exposed areas, (6) solutions regarding the physical risk factors of the work task, (7) comments of the employer after installation of the solution, (8) if necessary, additional comments of the ergonomist and (9) research references (if available).

\section{Results and discussion}

In total, 103 company visits were organised, 55 reports were sent and 143 good practices were found (task 1: 59; task 2: 29; task 3: 15; task 4: 7; task 5: 16; task 6: 16) The exposed areas (table 1) differed largely according to work task. In $39 \%$ of the farm visits, problems of the lower limbs (hip, legs and/or feet) were found for milking cows, whereas for harvesting no problems were observed. Low back problems were seen in almost all cases. Regarding the risk factors, posture problems were almost always observed, followed by frequency or duration problems (table 2).

All the good practices were summarised in 6 brochures. In each brochure, a short introduction with general description of the task was given. For each subtask, a short overview of MSD risks was given, followed by the different solutions to reduce the risks of MSD. As stated above, the solutions are presented in the order of going from easy, low-cost solutions to higher technological, more expensive solutions. An example is given in table 1 that represents the solutions for reducing physical load during all the subtasks of the task 'milking cows'. 


\section{ADJUSTABLE FLOOR}

\section{Task Description:}

In the parlour / rotary milking systems the milker stands in a ditch / on a rotating platform with a fixed floor. Milking is performed in an upright standing position and for several hours. The fixed floor is not adjustable to the height of the milker and this may complicate a correct working posture

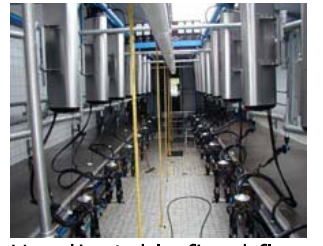

Unadjustable fixed floors in a milking parlour and in a rotary milking system

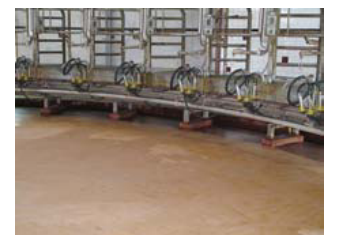

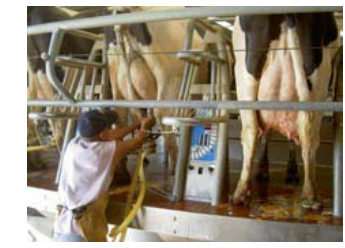

Unsuitable working posture when there is no adjustable floor installed

\section{Comments from the employee:}

- 'The work height is not in accordance with the work task'

a 'It is complicated to obtain a correct working posture'

a 'It is no comfortable standing posture'

a 'After milking, I always have pains in my shoulders and lower back'

\section{MSD risks:}

a The work involves working with the arms above shoulder height

a The posture complicates a correct angle of $90^{\circ}$ between the joints of the shoulder and the elbow

The milker is exposed to a continuously static muscle load for several hours

\section{Exposed areas: \\ a Neck / shoulder \\ Elbow \\ U Upper / lower back}

\section{Solutions:}

Installation of a floor in the milking parlour / rotary milking system which is adjustable to the height of the milker
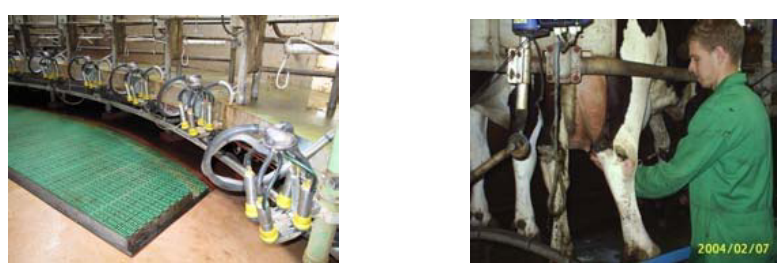

A floor in the milking parlour adjustable to the height of the milker

Comments from the employer after installation of an adjustable floor:

a 'The milkers complain less about aches and pains after milking the cows'

a 'In order to attract and keep good workers, it is important to have a good work environment and an adjustable floor in the parlour is a good example'

a 'The economic investment is well covered by the lower costs for sick leave'

\section{Comments from the ergonomist:}

a 'An adjustable floor is a good solution when there is one milker in the parlour. It is more complicated to adjust to a correct working height if there is two milkers of different body height milking at the same time'

\section{Research references:}

Stål, M. \& Pinzke, S. 1991. Work environment in dairy barns. Part 2. Musculoskeletal problems in Swedish milking parlour operators (In Swedish). Report no. 80. Department of Farm Building, Swedish University of Agricultural Sciences, Sweden.

Photos: Christina Kolstrup, Sweden, 2004; 2006; 2009

Figure 2: Example of the standard document for collecting good practices 
Table 1

Percentage of observed exposed areas during the farm visits. Task $1=$ milking cows, task $2=$ tractor driving, $\mathrm{t}$ ask $3=$ ground manual work, task $4=$ pruning, task $5=$ sorting, task $6=$ harvesting.

Task 2

Task 3

Task 4

Task 5

Task 6

neck/shoulder

$75 \%$

lower limbs

$39 \%$

$7 \%$

$6 \%$

$71 \%$

$100 \%$

$81 \%$

arm/wrist

$56 \%$

$0 \%$

$33 \%$

$0 \%$

$88 \%$

$0 \%$

lower back

$75 \%$

$3 \%$

$13 \%$

$57 \%$

$25 \%$

$38 \%$

posture

$98 \%$

$93 \%$

$100 \%$

$100 \%$

$88 \%$

$100 \%$

97\%

$100 \%$

$100 \%$

$100 \%$

$88 \%$

Table 2

Percentage of observed risk factors during the farm visits. Task $1=$ milking cows, task $2=$ tractor driving, task $3=$ ground manual work, task $4=$ pruning, task $5=$ sorting, task $6=$ harvesting.

Task 1

posture

frequency/duration

force

repetition

vibrations
Task 2 $98 \%$

$42 \%$

$36 \%$

$3 \%$

$3 \%$
Task 3

$97 \%$

$90 \%$

$0 \%$

$0 \%$

$93 \%$
Task 4

$$
100 \%
$$$$
27 \%
$$$$
33 \%
$$$$
33 \%
$$

$0 \%$

1

Task 5

Task 6

$\begin{array}{rr}100 \% & 88 \% \\ 56 \% & 56 \% \\ 25 \% & 81 \% \\ 25 \% & 19 \% \\ 0 \% & 0 \%\end{array}$

Table 3

Example of solutions to reduce MSD during milking cows.

\begin{tabular}{|l|l|}
\hline Subtask & Solutions \\
\hline Hand milking & Milking stool \\
& Table for filtering milk \\
\hline Udder cleaning & Centralised paper roll \\
& Paper cart \\
& Stationary location (rotary parlour) \\
& Automatic cleaning \\
& Adjustable floor (also for other tasks) \\
& Perforated rubber matting (also for other tasks) \\
\hline Attaching clusters & Support arm \\
& Spring-loaded long-travel arm \\
& Light-weight clusters \\
& Assisted button to release cluster \\
\hline Teat dipping & Spray bottle \\
& Automatic disinfectant spray \\
\hline Cleaning the floor & Adjustable handle length \\
& Water hose with pistol grip and automatic spraying \\
& Automatic cleaning by robot milking system \\
\hline Cleaning manure & Power driven manure slide \\
& Electrical manure slide \\
& Robot scraper or mobile barn cleaner \\
\hline
\end{tabular}


It is important to mention that the examples presented in the brochures do not claim to be totally complete regarding all possible good practices to prevent MSD, but are the results of farm visits. There was no affiliation to commercial organizations or products in presenting these good practices. All the examples, brochures and background information of the project are presented on the website: (www.agriergonomics.eu). At the end of the project, a seminar was organised for the EU social partners. They are responsible themselves to further distribute the information to their national organisations. For example in Belgium, the website and the brochures were presented to the national agricultural organisations and brochures were freely distributed to farming schools. But, compared with other sectors, agriculture has a number of distinct characteristics which makes it difficult to reach all farmers. In particular: the spread of atypical employment and the continuing similarities between farms as a production unit and as a household unit [7]. 59\% of the labour force is selfemployed [8]. Risk prevention for MSD is in general covered by existing European legislation, but this legislation is not always implemented in these smaller farms or enterprises. These small businesses have often low profit margins and therefore available funding for activities that they consider not to be associated with operational efficiency, may be limited [14]. Furthermore, although there is a major progress in new technologies in agricultural practices, reliance on labour will always be a major cornerstone and thus manual handling will remain [10], again specifically in the smaller farms. Additional barriers can also be workforce issues such as temporary and migrant workers with language barriers [14]. Recently, the social partners proposed to the European Commission to establish European observatories for $\mathrm{OSH}$ in the sector across Europe. By setting up these observatories, the sector hopes to reach more agricultural workers and to enhance prevention of MSD.

\section{Further research}

It is clear that there is much more to do in the sector beyond the 6 defined tasks and 99 solutions. Therefore this project could be considered as just a start, but also a model, in collecting good practices for other tasks (and even other sectors). Emphasis should also go to tasks where the physical circum- stances render the farm workers potentially vulnerable to MSDs of the lower limbs such as osteoarthritis of the hip and knee, as mentioned by WalkerBone and Palmer [13]. Furthermore, besides collecting good practices only in Europe, a world-wide project would even be more challenging. NIOSH presented in 2001 a resource for farm workers with 15 solutions to reduce the risk factors for MSD [12]. This and other resources could be brought together in a large database that would serve the agriculture sector in all countries. Finally, with the knowledge of the good practices, intervention programs could be set up based on an ergonomics approach. Chapman and Meyer [2] mention that one of the keys to successful intervention, is a cooperative partnership with involved farmers and farm workers and research scientists coupled with outreach specialists. Simple pamphleteering of the good practices alone will not accomplish the aims. It will require knowledgeable and trusted agents interacting with farm owners and workers to change the farm perspective on MSD and to think about prevention.

\section{Acknowledgement}

The project was funded by the European Commission, DG Employment, social affairs and equal opportunities (project number VS/2008/0530).

The authors would especially like to thank all the farmers and organisations that collaborated in this study.

\section{References}

[1] S. Baron, C. Estill, A. Steege, NN. Lalich, Simple solutions: ergonomics for farm workers. Cincinnati OH: US National Institute for Occupational Safety and Health (2001), 46 p.

[2] L. Chapman and J. Meyers, Ergonomics and musculoskeletal injuries in agriculture: recognizing and preventing the industry's most widespread health and safety problem National Ag Safety Database, 2001, http://www.cdc.gov/NASD/docs/ d001701-d001800/d001771/d001771.pdf

[3] B. Christophe and T. Mathias, Troubles musculosquelettiques en agriculture, La revue du practicien 57 (2007), 45-50.

[4] K.G. Davis, Understanding the ergonomic risk for musculoskeletal disorders in the United States agricultural sector. Am. J. Ind. Med., 50-7 (2007), 501-511.

[5] EFFAT and GEOPA European agreement of the agricultural social partners concerning musculoskeletal disorders (2005). Retrieved August 27th, 2010, from http://ec.europa.eu/employment_social/dsw/public/actRetrieve Text.do?id=10625. 
[6] European Agency for Safety and Health at Work, Good practice information. Retrieved July $28^{\text {th }}, 2011$ from: http://osha.europa.eu/en/practical-solutions

[7] European Foundation for the Improvement of Living and Working Conditions (2007), Representativeness of the social partners: agricultural sector. Retrieved July 28th, 2011, from http://www.eurofound.europa.eu/eiro/studies/tn0608017s/inde x.htm.

[8] European Foundation for the Improvement of Living and Working Conditions (2009), Agriculture and Fishing: EF/08/14/EN1. Retrieved August 27th, 2010, from http://osha.europa.eu/en/practical-solutions.

[9] European Foundation for the Improvement of Living and Working Conditions (2010), Fifth European Working Conditions Survey. Retrieved July 28th, 2011, from http://www.eurofound.europa.eu/surveys/ewcs/2010/index.ht $\mathrm{m}$.
[10]F.A. Fathallah, Musculoskeletal disorders in labor-intensive agriculture, Applied Ergonomics, 41-6 (2010), 738-743.

$[11] \mathrm{K}$. Kogi, How to support the participatory planning of practical workplace improvements, In Göbel $M$ et al. Human Factors in organizational Design and Management I, IEA Press: Santa Monica, 2011, pp. 3-8.

[12]D.M. Kramer, P.L. Bigelow, N. Carlan, R.P. Wells, E. Garrritano, P. Vi and M. Plawinski,. Searching for needles in a haystack: identifying innovations to prevent MSDs in the construction sector. Applied Ergonomics 42 (2010), 577-584.

[13]M. Sesto, Chronic musculoskeletal disorders in agriculture for partners in agricultural health, University of WisconsinMadison. worh.org/files/AgHealth/musc.pdf

[14] K. Walker-Bone and K.T. Palmer K.T, Musculoskeletal disorders in farmers and farm workers, Occup. Med. 52 (8) (2002), 441-450. 